\title{
Carbon Distribution in Ferritic-Martensitic Fe-Cr-C Alloys
}

\author{
Milan Jovan Konstantinovića* ${ }^{\circledR}$, Boris Minov ${ }^{a}$, Wouter Van Renterghem ${ }^{a}$ \\ ${ }^{a}$ Studiecentrum voor Kernenergie, Centre d'Étude de l'énergie Nucléaire - SCK•CEN, \\ Boeretang 200, $2400 \mathrm{Mol}$, Belgium
}

Received: September 29, 2017; Revised: March 05, 2018; Accepted: April 20, 2018

\begin{abstract}
Carbon distribution in $\mathrm{Fe}-\mathrm{Cr}-\mathrm{C}$ alloys with a variety of $\mathrm{Cr}$ concentrations is studied based on internal friction, optical and transmission-electron microscopy. It is found that the carbon distribution strongly depends on initial microstructure, being ferritic or ferritic/martensitic, which is determined by the thermal treatment, and $\mathrm{Cr}$ and carbon concentrations. In the quenched alloys, carbon is observed in the form of small carbon-vacancy complexes, most probably two carbon - single vacancy cluster, $2 \mathrm{CV}$, that dissolve at about $500 \mathrm{~K}$. In tempered alloys, the carbon atoms are observed to be uniformly distributed only in $\mathrm{Fe}-2.5 \mathrm{Cr}-\mathrm{C}$ alloy, which is fully ferrite. In the alloys with $5-12 \%$ of Cr, with ferritic/martensitic microstructure, carbon-Snoek relaxation peak is not observed due to the carbon precipitation, as well as due to atomic carbon being trapped at dislocations and grain boundaries. In both quenched and tempered alloys, the plastic deformation causes the appearance of the broad relaxation peak close to $300 \mathrm{~K}$ which could be assigned to dissolution of single carbon - single vacancy, CV, complexes.
\end{abstract}

Keywords: $\mathrm{Fe}-\mathrm{Cr}$-C alloys, internal friction, ferritic-martensitic microstructure.

\section{Introduction}

Variety of phases and microstructures which can occur in iron alloys and steels strongly depend on the amount of carbon, heat treatment of the alloy, and distribution of carbon atoms in the lattice, e.g. as an interstitial or in the form of carbides. Moreover, carbon easily segregates at dislocations and grain boundaries, and shows a great affinity to bind with irradiation-induced defects such as vacancies, solute clusters and precipitates ${ }^{1,2}$. Consequently, the carbon distribution has a strong influence on defect formation and mobility, thus affecting the materials mechanical properties including the swelling of irradiated materials. Moreover, a better understanding of the carbon distribution processes should help to improve the correlation between the microstructure and mechanical properties. This is particularly important in ferritic-martensitic (F/M) steels, which are considered as candidate structural materials for a future generation of nuclear reactors ${ }^{3}$.

In this study we analyze the carbon distribution induced by the thermal treatment of Fe-Cr-C alloys. These alloys can be regarded as the model alloys of $\mathrm{F} / \mathrm{M}$ steels. By varying $\mathrm{Cr}$ and $\mathrm{C}$ concentrations, we investigate the phase-evolution of initial microstructure in Fe-Cr-C alloys, as well the effect of microstructural variations to the carbon distribution processes, on the basis of internal friction (IF), light optical microscopy (LOM), and transmission electron microscopy (TEM) techniques.
In contrast to other microstructural characterization techniques, the IF technique provides unique possibility to detect carbon in the lattice, through the measurement of Debye relaxation processes ${ }^{4}$. In nominally pure $\alpha$-iron, the thermal motion of interstitially dissolved carbon atoms is known as the Snoek-relaxation peak ${ }^{5}$. Snoek relaxation process was previously also investigated in $\mathrm{Fe}-\mathrm{Cr}-\mathrm{C}$ alloys ${ }^{6}$. Temperature position of the Snoek-peak was found to be dependent on $\mathrm{Cr}$ concentration due to increase of activation energy for carbon jumps between interstitial positions. Besides Snoek-peak, recent analysis of relaxation processes, which occur in the IF spectra of a variety of $\mathrm{Fe}-\mathrm{C}$ alloys with different carbon concentrations and out-of-equilibrium vacancy concentrations, demonstrated the observation of relaxation processes due to dissolution of small carbon-vacancy complexes ${ }^{7}$. In addition to the relaxation technique, we also employed LOM and TEM in order to follow the microstructural evolution of Fe-Cr-C alloys progressively with the heat treatment. In particular, TEM was used to estimate the grain size and dislocation density in these alloys.

As a result, we have at hand the methodology to fully determine the carbon distribution in complex systems such as Fe-Cr-C alloys, as well as to follow it at various stages in the alloy production process. 


\section{Materials}

$\mathrm{Fe}-\mathrm{Cr}-\mathrm{C}$ alloys were fabricated by furnace melting of industrial $\mathrm{Fe}$ (containing carbon) and $\mathrm{Cr}$. After casting, the obtained ingots were cold worked under protective atmosphere to fabricate plates (to avoid oxidation), which were further annealed for $3 \mathrm{~h}$ at $1320 \mathrm{~K}$ in a high vacuum (to prevent surface reactions) for austenitization. This treatment was followed by air quenching to room temperature. Parts of the plates were preserved for the investigation, while the rest of the material was normalized by tempering for $4 \mathrm{~h}$ at $1000 \mathrm{~K}$ followed by air-cooling. The tempering, as an integral part of a heat treatment procedure of commercial F/M steels, is done in order to release quench-induced stresses in the material. The IF, TEM and LOM samples are made from both parts of the plates and they are henceforth termed as "as-quenched" and "tempered", respectively. The chemical composition of each alloy was determined by using induced coupled plasma mass spectrometry (ICP-MS), and it is shown in Table $1^{8}$.

The IF samples had atypical size of $1.3 \times 1.3 \times 30 \mathrm{~mm}^{3}$. The second set of IF samples was, in a consistent way, subjected to a torsional cyclic plastic deformation by an angle of $\pi / 2$ over a length of $30 \mathrm{~mm}$ at room temperature prior to the measurements.

After mechanical polishing, the LOM Fe-Cr-C samples were chemically etched in the solution made of $100 \mathrm{ml}$ ethyl alcohol and $3 \mathrm{ml} \mathrm{HNO}_{3}$. The polishing process and subsequent etching were carried out at room temperature.

For the TEM sample preparation, thin slices were cut from the bulk of each alloy and mechanically polished to a thickness of about $100 \mu \mathrm{m}$. Afterwards, $3 \mathrm{~mm}$ discs were punched out of the polished slice. The final step in the specimen preparation was electrochemical polishing at 223 $\mathrm{K}$ with an applied voltage of $40 \mathrm{~V}$.

\section{Experiments}

The IF spectra were measured in an inverted torsional pendulum, at a frequency of about $2 \mathrm{~Hz}$, in a temperature range from 100 to $650 \mathrm{~K}$. The IF coefficient $\mathrm{Q}^{-1}$ is determined from the free decay signal. The measurements were performed at a strain amplitude of about $10^{-4}$ in a He atmosphere with a heating rate of about $1.5 \mathrm{~K} / \mathrm{min}$, and no magnetic field was applied.
The LOM was used for the metallographic examination. The image from an optical microscope was captured by a charge-coupled device (CCD) camera.

The TEM specimens were investigated in a JEOL 3010 instrument operating at $300 \mathrm{kV}$. Conventional microscopy techniques including bright field, dark field, diffraction pattern, convergent beam electron diffraction, and weak beam imaging were applied. The local composition is confirmed with energy dispersive X-ray spectroscopy (EDS).

\section{Results and Discussions}

The Fe-Cr-C alloys are presented and analyzed following a heat treatment procedure. First, an analysis of as-quenched and tempered alloys are given. Afterwards, the results of cold-worked alloys, both of quenched and tempered alloys are presented and discussed.

The LOM micrographs of the as-quenched Fe-Cr-C alloys are shown in Figure 1. It can be seen that by the increase of $\mathrm{Cr}$ content, the microstructure changes from fully ferritic to ferrite/martensite. The microstructure shown in Figure 1 (a) is a typical ferrite structure, while Fe-5, 9 and $12 \mathrm{Cr}-\mathrm{C}$ alloys, shown in Figure 1(b-d), are characterized by the presence of the packets (martensite laths), which are formed during the quench in the prior austenitic grains. However, due to the difficulties in identification of the packet boundaries in the prior austenitic grains, it is impossible to compare the sizes of the grains in these alloys by LOM.

For that purpose the TEM measurements are performed and the micrographs of the as-quenched $\mathrm{Fe}-\mathrm{Cr}-\mathrm{C}$ alloys are shown in Figure 2. Indeed, the structure of Fe-2.5Cr-C alloy, shown in Figure 2(a), is a typical ferrite structure consisted of large grains separated by high-angle boundaries. On the other hand, the microstructures of other alloys show the presence of the martensite laths surrounded by small ferrite grains, see Figures 2(b-d). The common characteristic of all alloys is the presence of a large number of dislocations. By increasing the $\mathrm{Cr}$ content in these alloys, the density of dislocations increases to such extent that the individual dislocations in the F/M alloys are difficult to identify at some places. Still, an estimate of dislocation density is performed, and the results are summarized in Table 2.

The temperature-dependent IF spectra of the as-quenched alloys are shown in Fig. 3.

Table 1. Chemical composition of the alloys (wt.\%). The relative standard deviation for all elements was $<3 \%$.

\begin{tabular}{|c|c|c|c|c|c|c|c|c|c|c|c|c|}
\hline \multirow{2}{*}{ Materials } & \multicolumn{12}{|c|}{ Composition in wt.\% } \\
\hline & $\mathrm{Cr}$ & $\mathrm{Si}$ & $\mathrm{P}$ & $\mathrm{Ni}$ & $\mathrm{C}$ & $\mathrm{Al}$ & $\mathrm{S}$ & $\mathrm{Ti}$ & V & $\mathrm{N}$ & $\mathrm{Mn}$ & $\mathrm{O}$ \\
\hline $\mathrm{Fe}-2.5 \% \mathrm{Cr}$ & 2.4 & 0.02 & 0.02 & 0.04 & 0.008 & 0.006 & 0.004 & 0.005 & 0.001 & 0.05 & 0.01 & 0.035 \\
\hline $\mathrm{Fe}-5 \% \mathrm{Cr}$ & 4.6 & 0.04 & 0.02 & 0.06 & 0.02 & 0.001 & 0.01 & 0.003 & 0.001 & 0.05 & 0.02 & 0.065 \\
\hline $\mathrm{Fe}-9 \% \mathrm{Cr}$ & 8.4 & 0.09 & 0.02 & 0.07 & 0.02 & 0.014 & 0.001 & 0.004 & 0.002 & 0.06 & 0.03 & 0.066 \\
\hline $\mathrm{Fe}-12 \% \mathrm{Cr}$ & 11.6 & 0.11 & 0.09 & 0.09 & 0.03 & 0.006 & 0.012 & 0.004 & 0.002 & 0.09 & 0.03 & 0.03 \\
\hline
\end{tabular}



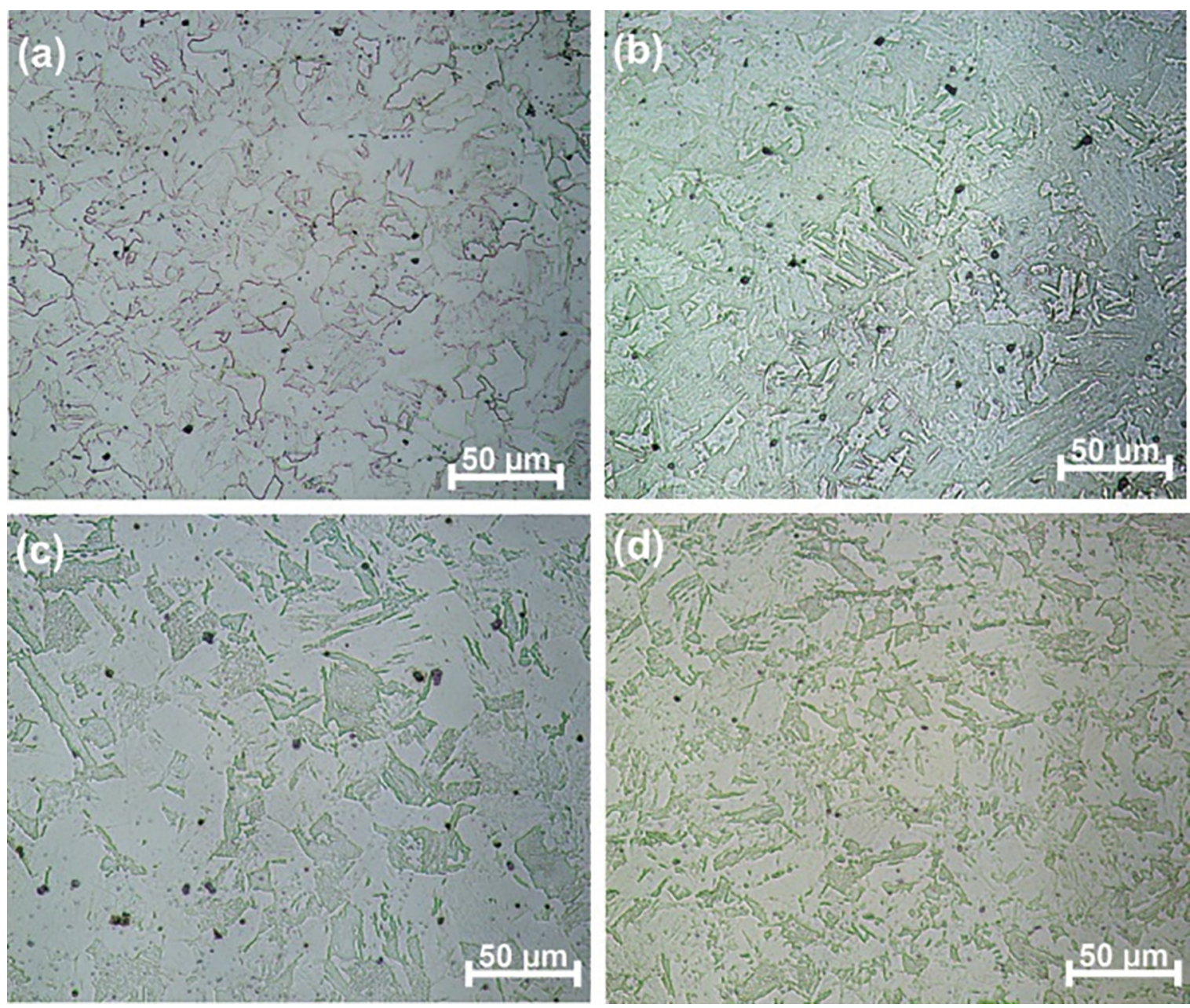

Figure 1. Light optical microscopy pictures of the as-quenched (a) Fe-2.5Cr-C, (b) Fe-5Cr-C, (c) Fe-9Cr-C, and (d) Fe-12Cr-C alloys.

The spectrum of the $\mathrm{Fe}-2.5 \mathrm{Cr}-\mathrm{C}$ alloy is mainly composed of the peak centered at about $460 \mathrm{~K}$ and denoted as $2 \mathrm{CV}$, which, according to the peak parameters, is assigned to dissolution of small carbon-vacancy complex, namely, $2 \mathrm{CV}$ complex ${ }^{5}$. The 2CV-peak differs in $\mathrm{Fe}-2.5 \mathrm{Cr}$-C alloy with respect to other alloys. Namely, in Fe-5Cr-C, Fe-9Cr-C, and $\mathrm{Fe}-12 \mathrm{Cr}-\mathrm{C}$ this peak shifts by about $50-70 \mathrm{~K}$ towards higher temperatures and broadens, see Figure 3(b-d). Similar temperature shift and the broadening of $2 \mathrm{CV}$ peaks is also observed after plastic deformation, see Fig 8. Broadening could be the consequence of lattice distortions due to the presence of martensites. Broadening is the largest in $\mathrm{Fe}-12 \mathrm{Cr}-\mathrm{C}$ alloy, which also exhibits the highest amount of martensites, see Figs. 1 and 2. Interestingly, the temperature shift is not observed in the case of CV peak that appears after plastic deformation, see Fig. 7 and 8. Most probably, the presence of $\mathrm{Cr}$ and/or martensite lattice distortions affect mainly carbon - carbon interaction within $2 \mathrm{CV}$ cluster. As a result, $\mathrm{C}-\mathrm{C}$ repulsion is reduced causing higher stability of $2 \mathrm{CV}$ cluster in high-Cr alloys.
Integrated intensity of $2 \mathrm{CV}$ peak increases by increasing the $\mathrm{Cr}$ content. The reason for this is the fact that $\mathrm{Fe}-12 \mathrm{Cr}-\mathrm{C}$ alloys has the highest carbon concentration, while $\mathrm{Fe}$ 2.5Cr-C has the lowest, see Table 1. Even though the carbon content is the same in $\mathrm{Fe}-5 \mathrm{Cr}-\mathrm{C}$ and $\mathrm{Fe}-9 \mathrm{Cr}-\mathrm{C}$ alloys, small difference between the $2 \mathrm{CV}$ peak intensities is still observed in the IF spectra. This effect could be the consequence of fluctuations in annealing temperature and quenching times (experimental uncertainties).

In addition to the $2 \mathrm{CV}$-peak $\mathrm{Fe}-2.5 \mathrm{Cr}$-C samples also shows the existence of the weak Snoek-peak which corresponds to the relaxation process of carbon atoms in the interstitial positions ${ }^{4}$.

The observation of a large number of dislocations agrees well with the IF spectra, which show well-pronounced CV dissolution peaks. After quenching, both high dislocation density as well as out-of-equilibrium concentration of vacancies, as being responsible for the formation of $\mathrm{C}-\mathrm{V}$ complexes, are expected. 


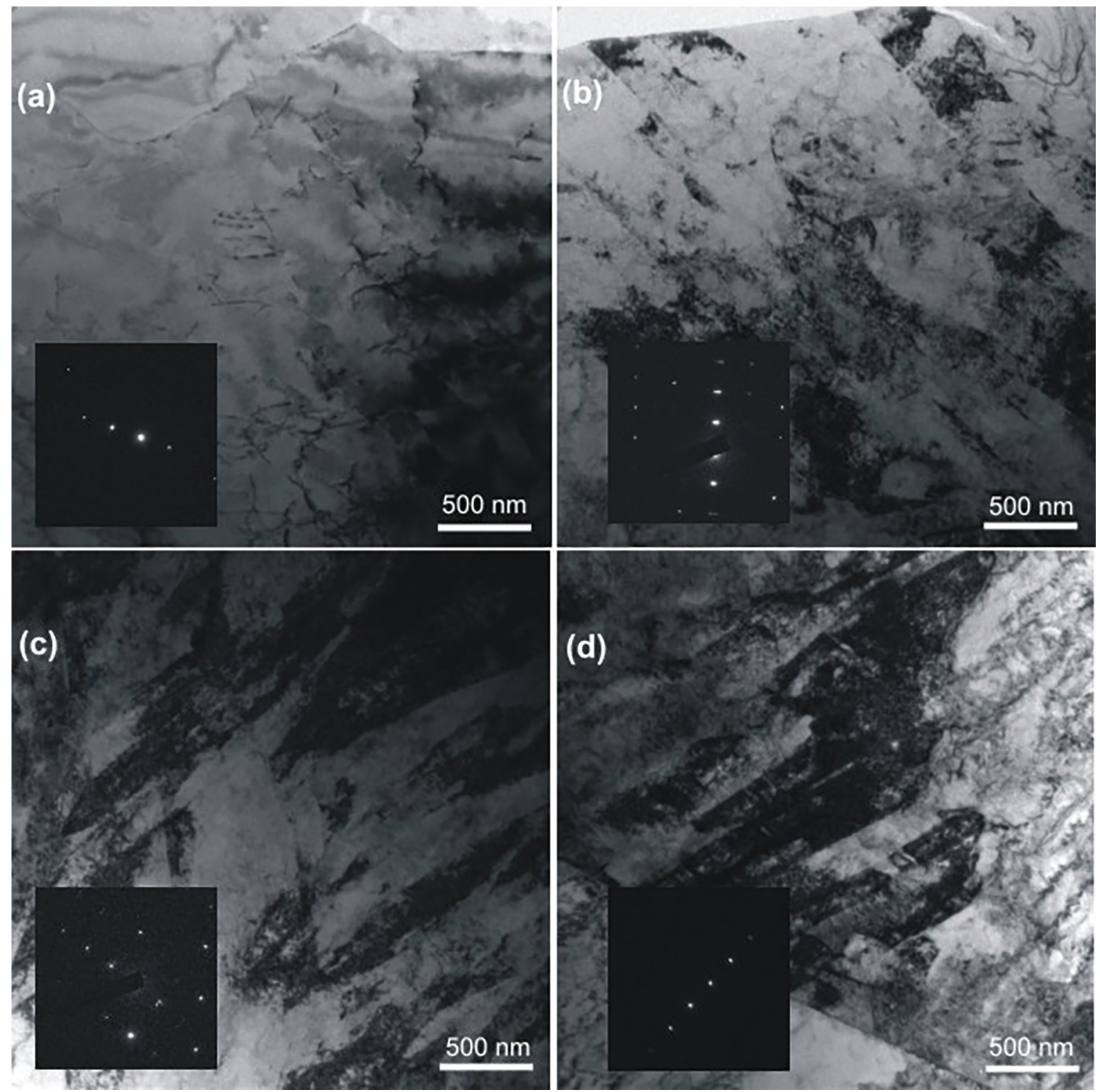

Figure 2. Bright field transmission electron microscopy images of the as-quenched (a) Fe-2.5Cr-C, (b) Fe-5Cr-C, (c) Fe-9Cr-C, and (d) Fe-12Cr-C alloys. Diffraction patterns is shown on the bottom left of each image.

Table 2. Average grain size, lath width and dislocation density of quenched and tempered $\mathrm{Fe}-\mathrm{Cr}-\mathrm{C}$ alloys

\begin{tabular}{llcccc}
\hline alloy & & Fe-2.5-Cr-C & Fe-5Cr-C & Fe-9Cr-C & Fe-12Cr-C \\
\hline microstructure & & ferrite & ferrite $/$ martensite & ferrite $/$ martensite & ferrite $/$ martensite \\
\hline \multirow{2}{*}{ quenched } & grain size & $15 \pm 5 \mu \mathrm{m}$ & - & - & - \\
& lath width & - & $250 \pm 70 \mathrm{~nm}$ & $150 \pm 50 \mathrm{~nm}$ & $150 \pm 50 \mathrm{~nm}$ \\
& dislocation density & $3 \pm 1 \times 10^{14} / \mathrm{m}^{2}$ & $1.5 \pm 0.5 \times 10^{15} / \mathrm{m}^{2}$ & $8 \pm 2 \times 10^{14} / \mathrm{m}^{2}$ & $1 \pm 0.3 \times 10^{15} / \mathrm{m}^{2}$ \\
& grain size & $60 \pm 15 \mu \mathrm{m}$ & $15 \pm 5 \mu \mathrm{m}$ & $5 \pm 2 \mu \mathrm{m}$ & $4 \pm 2 \mu \mathrm{m}$ \\
tempered & lath width & - & $0.5-5 \mu \mathrm{m}$ & $0.5-5 \mu \mathrm{m}$ & $0.5-5 \mu \mathrm{m}$ \\
& dislocation density & $2 \pm 1 \times 10^{14} / \mathrm{m}^{2}$ & $2 \pm 1 \times 10^{14} / \mathrm{m}^{2}$ & $2 \pm 1 \times 10^{14} / \mathrm{m}^{2}$ & $2 \pm 1 \times 10^{14} / \mathrm{m}^{2}$ \\
& & inhomogeneous & inhomogeneous & inhomogeneous & inhomogeneous \\
\hline
\end{tabular}




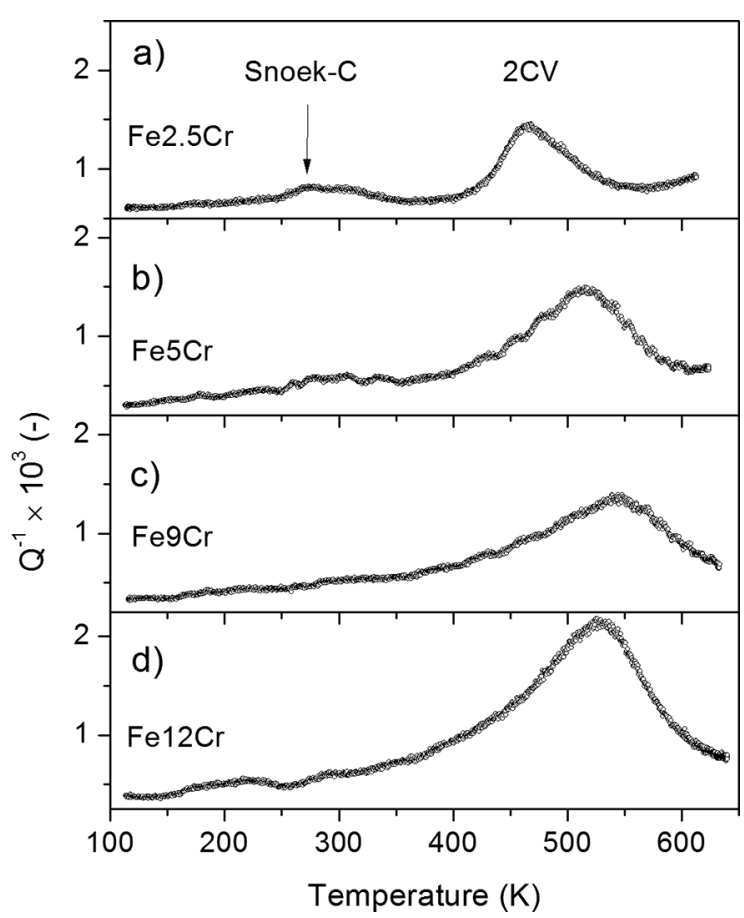

Figure 3. Temperature-dependent internal friction spectra of the as-quenched (a) $\mathrm{Fe}-2.5 \mathrm{Cr}-\mathrm{C}$, (b) $\mathrm{Fe}-5 \mathrm{Cr}-\mathrm{C}$, (c) $\mathrm{Fe}-9 \mathrm{Cr}-\mathrm{C}$, and (d) $\mathrm{Fe}-12 \mathrm{Cr}-\mathrm{C}$ alloys.
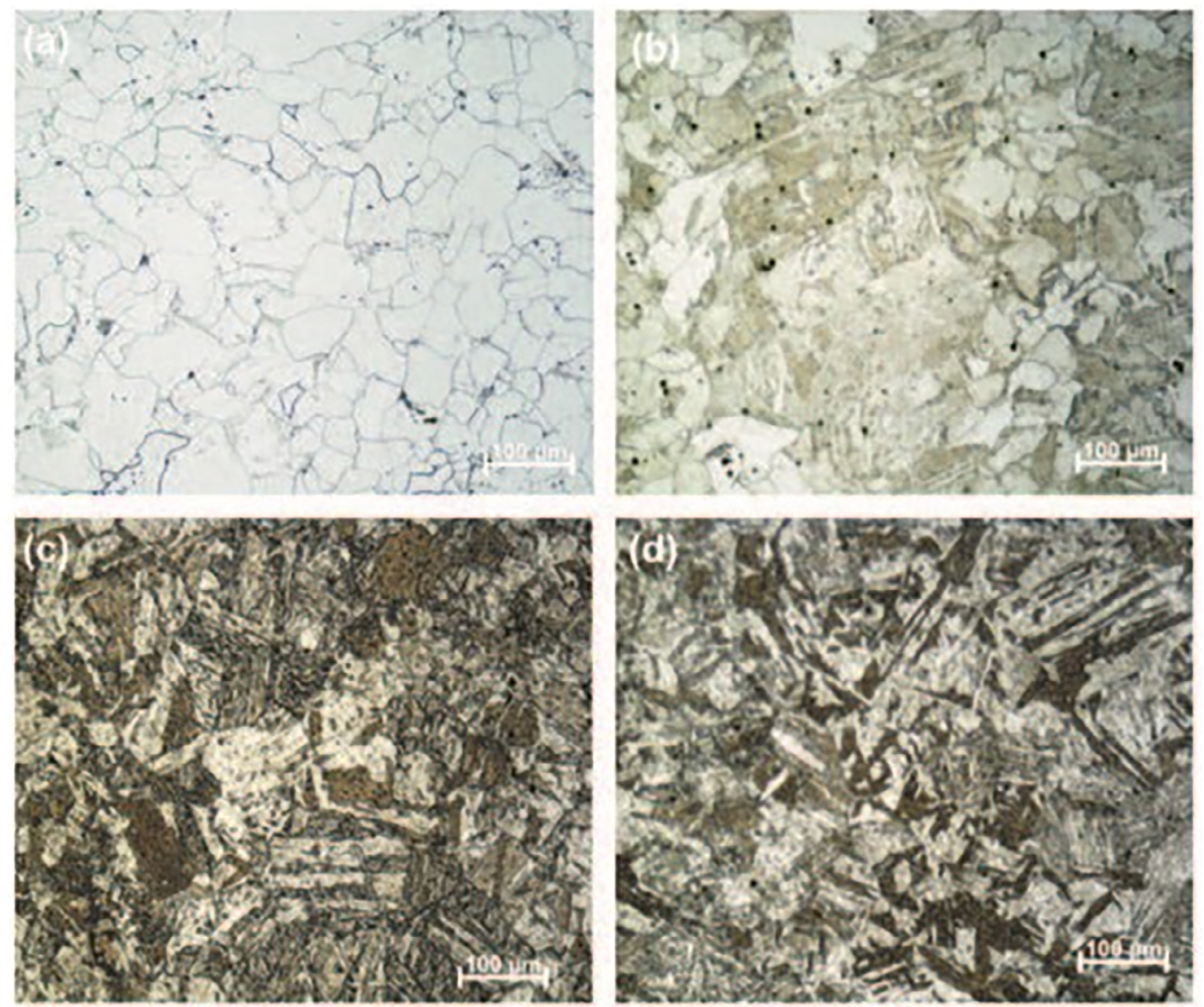

Figure 4. Light optical microscopy pictures of the tempered (a) Fe-2.5Cr-C, (b) Fe-5Cr-C, (c) Fe-9Cr-C, and (d) Fe1-2Cr-C alloys. 

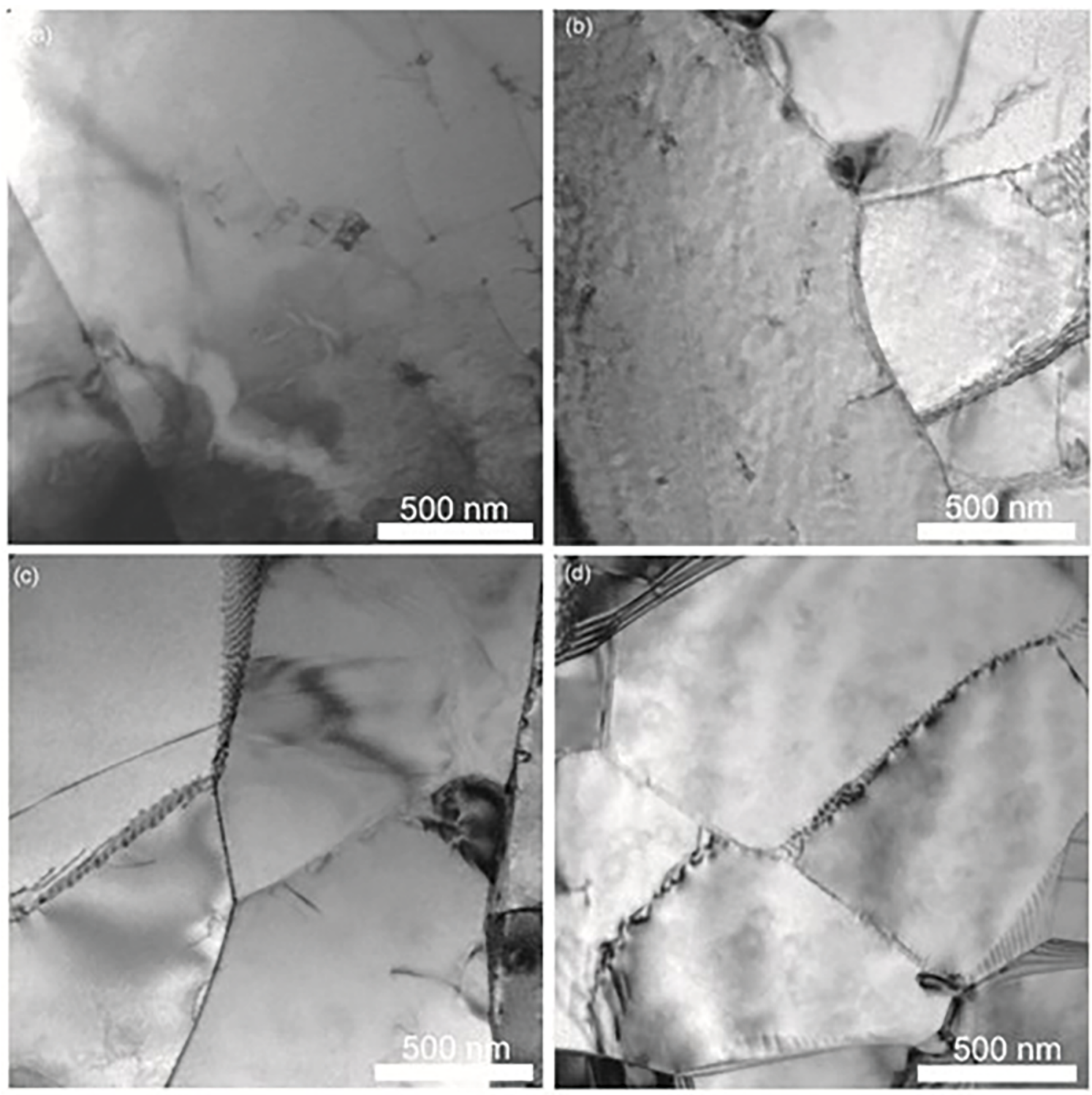

Figure 5. Bright field transmission electron microscopy images of the tempered (a) $\mathrm{Fe}-2.5 \mathrm{Cr}-\mathrm{C}$, (b) $\mathrm{Fe}-5 \mathrm{Cr}-\mathrm{C}$, (c) $\mathrm{Fe}-9 \mathrm{Cr}-\mathrm{C}$, and (d) $\mathrm{Fe}-12 \mathrm{Cr}-\mathrm{C}$ alloys.

Figures 4 and 5 show the microstructures of the alloys obtained after the tempering.

All alloys exhibit an increase of the grain size after tempering, see Figure 4. This is consistently observed in Fe-2.5Cr-C alloy, see Figure 4 (a), as in Fe-5Cr-C, Fe-9Cr-C, and $\mathrm{Fe}-12 \mathrm{Cr}-\mathrm{C}$ alloys, see Figure 5(b-d). Still, both LOM and TEM micrographs indicate that the grain sizes of the later alloys are smaller in comparison with $\mathrm{Fe}-2.5 \mathrm{Cr}-\mathrm{C}$ alloy, see Figures 4 and 5 . The increased mobility of dislocations during recrystallization caused an annihilation of the small angle grain boundaries in the martensite phase, see Figure 5. As a result, $\mathrm{Fe}-5,9$, and $12 \mathrm{Cr}-\mathrm{C}$ alloys show drastic reduction of the dislocation densities by about two orders of magnitude with respect to those in as-quenched structures. The IF spectra of the tempered samples are shown in Figure 6.
As expected and in agreement with the TEM observations, relaxation processes due to non-equilibrium conditions are observed. This indicates that dislocations and out of equilibrium vacancies are well annealed after tempering. The IF spectra of the tempered Fe-2.5Cr-C sample exhibit the Snoek-peak at about $305 \mathrm{~K}$. This indicates that in tempered alloys, the carbon atoms are uniformly distributed within the ferrite grains. In the alloys with $5-12 \%$ of $\mathrm{Cr}$, with ferritic-martensitic microstructure, free carbon signal is not observed due to the carbon precipitation, as well as due to atomic carbon being trapped at dislocations and grain boundaries. The shift of Snoek-peak as a function of chromium concentration, as reported in previous study, is not observed in this study. 


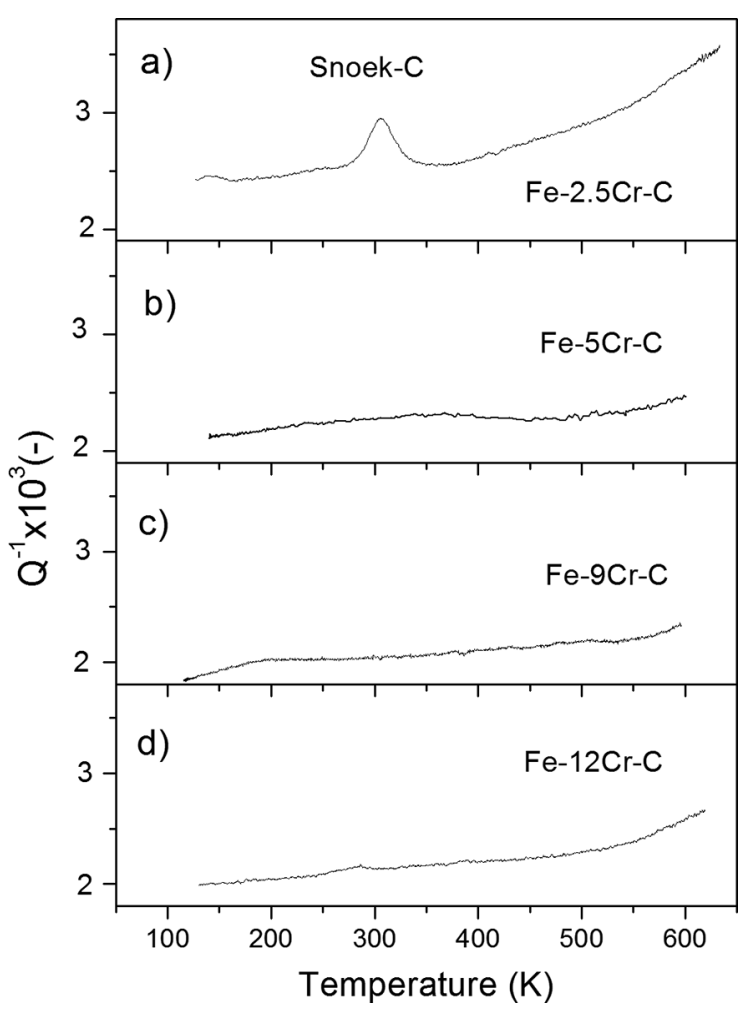

Figure 6. Temperature-dependent internal friction spectra of the tempered (a) $\mathrm{Fe}-2.5 \mathrm{Cr}-\mathrm{C}$, (b) $\mathrm{Fe}-5 \mathrm{Cr}-\mathrm{C}$, (c) $\mathrm{Fe}-9 \mathrm{Cr}-\mathrm{C}$, and (d) $\mathrm{Fe}-12 \mathrm{Cr}-\mathrm{C}$ alloys.

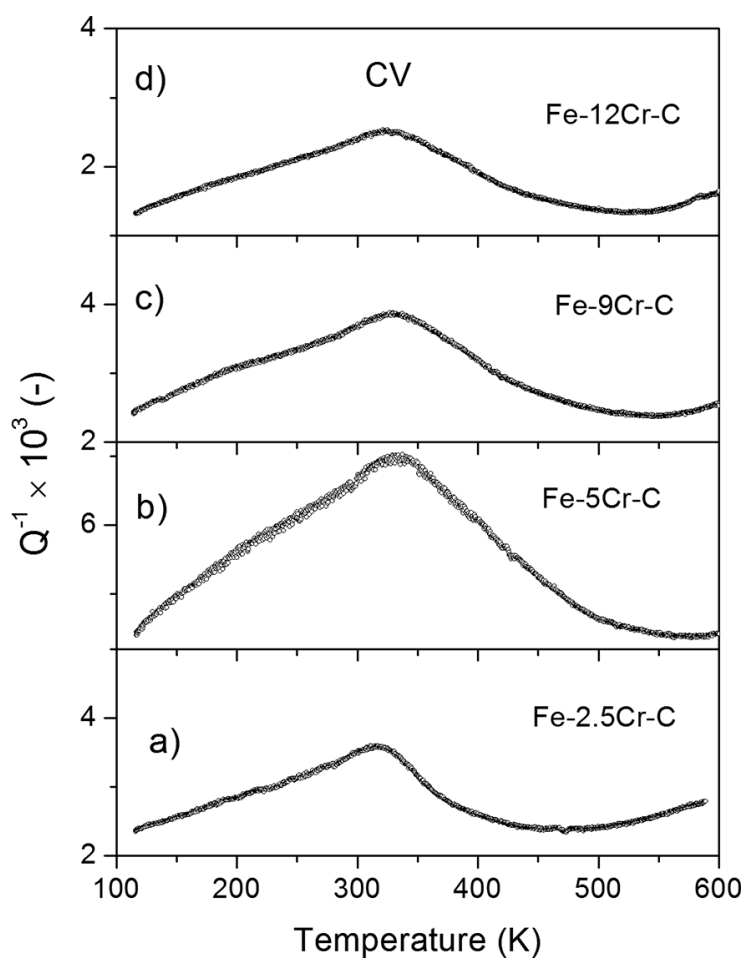

Figure 7. Temperature-dependent internal friction spectra of the cold-worked and tempered (a) Fe-2.5Cr-C, (b) Fe-5Cr-C, (c) $\mathrm{Fe}-9 \mathrm{Cr}-\mathrm{C}$, and (d) Fe-12Cr-C alloys.

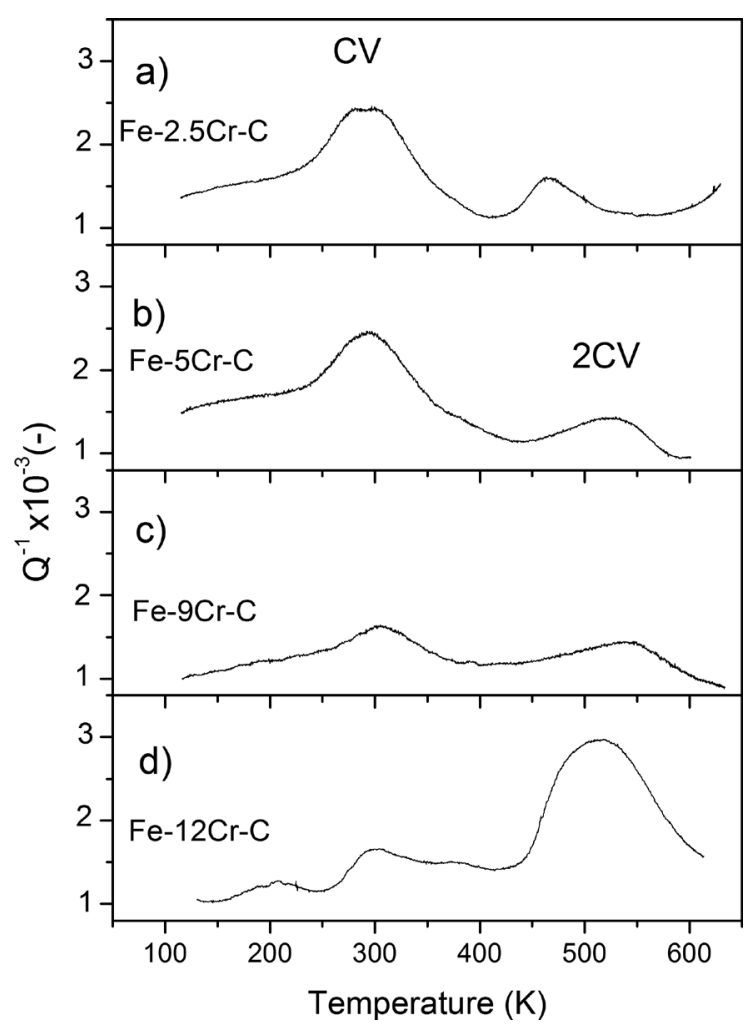

Figure 8. Temperature-dependent internal friction spectra of the cold-worked and quenched (a) Fe-2.5Cr-C, (b) Fe-5Cr-C, (c) Fe$9 \mathrm{Cr}-\mathrm{C}$, and (d) $\mathrm{Fe}-12 \mathrm{Cr}-\mathrm{C}$ alloys.

The annealing of small carbon-vacancy clusters and dislocations during tempering causes the removal of carbon atoms back to the interstitial positions in the lattice. This effect is clearly observed in ferritic $\mathrm{Fe}-2.5 \mathrm{Cr}-\mathrm{C}$ alloy. On the other hand, in $\mathrm{Fe}-5,9$, and $12 \mathrm{Cr}-\mathrm{C}$ alloys, tempering of martensite occurred via carbide precipitation and atomic carbon segregation at grain boundaries and dislocations.

Due to the cold work, the IF spectra of all alloys show the presence of a very broad structure centered at about $300 \mathrm{~K}$, se Figure 7. Similar structure is also observed in plastically deformed alloys after quenching, see Figure 8; however, it is superimposed to the relaxation peaks which are found in non-deformed quenched alloys. It seems that the relaxation process at about $300 \mathrm{~K}$ does not affect the dissolution process of CV clusters. According to the temperature position, $300 \mathrm{~K}$ peak is assigned to the dissolution of single carbon - single vacancy complex, namely $\mathrm{CV}$ complex ${ }^{5}$.

\section{Conclusion}

This study utilized a combination of internal friction, light optical microscopy and transmission electron microscopy techniques to get a comprehensive picture about the distribution of carbon atoms in thermally treated $\mathrm{Fe}-\mathrm{Cr}-\mathrm{C}$ alloys. 
The results of quenched and tempered Fe-Cr-C alloys provide the evidence that the carbon distribution strongly depends on the microstructure and thermal treatment. In the quenched alloys, irrespectively of $\mathrm{Cr}$ and carbon concentrations, carbon atoms are mainly associated to vacancies, which are created under out-of-equilibrium condition during fast cooling. What concerns tempered alloys, in ferritic alloys the carbon atoms are mainly located in the bcc lattice of ferrite grains, while in ferritic/martensitic alloys carbon mainly segregates at the (tempered) martensite grain boundaries and forms carbides.

\section{References}

1. Minov B, Lambrecht M, Terentyev D, Domain C, Konstantinovic MJ. Structure of nanoscale copper precipitates in neutron-irradiated Fe-Cu-C alloys. Physical Review B. 2012;85(2):024202.
2. Konstantinović MJ, Van Renterghem W, Matijašević M, Minov B, Lambrecht M, Toyama T, et al. Mechanical and microstructural properties of neutron irradiated Fe-Cr-C alloys. Physica Status Solid (a). 2016;213(11):2988-2994.

3. Zinkle SJ, Was GS. Materials challenges in nuclear energy. Acta Materialia. 2013;61(3):735-758.

4. De Batist R. Internal Friction of Structural Defects in Crystalline Solids. Amsterdam: North Holland; 1972.

5. Snoek JL. Effect of small quantities of carbon and nitrogen on the elastic and plastic properties of iron. Physica. 1941;8(7):711-733.

6. Golovin IS, Blanter MS, Schaller R. Snoek Relaxation in FeCr Alloys and Interstitial-Substitutional Interaction. Physica Status Solid (a). 1997;160(1):49-60.

7. Konstantinović MJ, Malerba L. Dissolution of carbon-vacancy complexes in Fe-C alloys. Physical Review Materials. 2017;1(5):053602.

8. Matijašević M. Microstructure and mechanical properties of $\mathrm{Fe}$-Cr model alloys and high Cr steels under neutron irradiation. [Thesis]. Ghent: Ghent University, 2008. 